\title{
Adherence to Self-isolation measures by older adults during coronavirus disease 2019 (COVID-19) epidemic: A phone survey in Iran
}

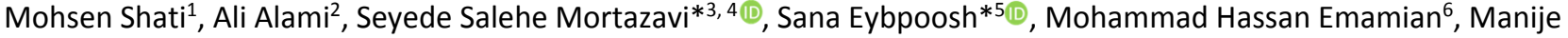 \\ Moghadam $^{7}$
}

Received: 20 Jul 2020

Published: 10 Nov 2020

\section{Abstract}

Background: Older adults are at higher risk for severe illness and death associated with coronavirus disease 2019 (COVID-19). As Iran was affected by COVID-19 pandemic, the elderly population soon were told to self-isolate for a very long time. We aimed to identify the coverage, efficacy, and integrity of self-isolation and its predictors in the Iranian older adults ( $\geq 60$ years) from February 19 to 19 March 2020.

Methods: Quota sampling was performed to recruit respondents from 16 cities that were selected based on their population size (4, 7 , and 5 cities for localities with $\leq 500000,500000-1000000$, and $\geq 1000000$ populations) and geographical direction (West $=4$ cities; North, East, South, Center $=3$ each). At least 30 respondents per locality were selected. Phone interviews of 558 respondents (out of 560; response rate $=99.6 \%$ ) were performed by local trained interviewers using a validated interview form. Association between age, sex, and living condition (with family vs alone) was assessed with Pearson Chi Square and logistic regression analyses.

Results: Complete self-isolation was reported by $61 \%$ of the respondents. In $72 \%$, self-isolation led to $80 \%-100 \%$ contact reduction. Self-isolation was broken by $26 \%$ of the respondents. Females had better self-isolation behaviors (OR adjusted: $2.3,95 \%$ CI: $1.5,3.3$ ) and higher contact reduction rates (p: 0.067). They kept the integrity of self-isolation better (OR adjusted: 1.8; 95\% CI: 1.2, 2.7). Those aged older than 80 years were 2.3 -folds more likely to completely self-isolate than younger elderly $(95 \% \mathrm{CI}$ adjusted: $1.2,4.3)$. Living alone did not significantly predict self-isolation features in the elderly.

Conclusion: About one third of the interviewed Iranian older adults did not adhere to important self-isolation measures, with males and younger ages showing lower adherence. With the relaxation of social distancing measures, protection measures of the elderly should be strengthened. Given that prolonged self-isolation adversely affects physical and mental health status of the elderly, it is highly recommended to think of creative and gender-specific methods that best tailor the needs of this population in Iran.

Keywords: Aged, COVID-19, Quarantine, Isolation, Iran

Conflicts of Interest: None declared

Funding: This study is supported by Shahroud University of Medical Sciences in Iran (Code: 9943).

\section{*This work has been published under CC BY-NC-SA 1.0 license.}

Copyright $\odot$ Iran University of Medical Sciences

Cite this article as: Shati M, Alami A, Mortazavi SS, Eybpoosh S, Emamian MH, Moghadam M. Adherence to Self-isolation measures by older adults during coronavirus disease 2019 (COVID-19) epidemic: A phone survey in Iran. Med J Islam Repub Iran. 2020 (10 Nov);34:152. https://doi.org/10.47176/mjiri.34.152

Corresponding author: Dr Seyede Salehe Mortazavi, mortazavi.ss@iums.ac.ir DrSana Eybpoosh, s_eybpoosh@pasteur.ac.ir

1. Mental Health Research Center, Psychosocial Health Research Institute, Iran University of Medical Sciences, Tehran, Iran

2. Department of Epidemiology and Biostatistics, School of Public Health, Social Determinants of Health Research Center, Gonabad University of Medical Sciences, Gonabad, Iran

3. School of Behavioral Sciences and Mental Health (Tehran Institute of Psychiatry) Iran University of Medical Sciences, Tehran, Iran

4. Spiritual Health Research Center, Iran University of Medical Sciences, Tehran, Iran.

5. Department of Epidemiology and Biostatistics, Research Centre for Emerging and Reemerging Infectious Diseases, Pasteur Institute of Iran, Tehran, Iran

6. Ophthalmic Epidemiology Research Center, Shahroud University of Medical Sciences, Shahroud, Iran

7. Department Of Older Adult Health, Ministry of health of Iran, Tehran, Iran $\uparrow$ What is “already known” in this topic:

COVID-19 patients' risk increases by age. A high proportion of severe COVID-19 cases and associated deaths in Iran belongs to the adults aged 60 . No vaccine is available yet and self-isolation and physical (social) distancing are proposed as the main prevention and control measures, especially in vulnerable populations, such as elderly. The elderly have certain psychological, medical and basic needs which make it difficult to adhere to self-isolation measures. The empirical evidence about the adherence of the elderly to self-isolation measures is lacking in Iran.

\section{$\rightarrow$ What this article adds:}

Our results showed about one-third of older adults in Iran do not completely adhere to self-isolation measures or have not maintained the integrity of self-isolation. In $70 \%$ of the elderly, self-isolation resulted in $80 \%-100 \%$ contact reduction. Others reported $<80 \%$ contact reduction. Males and younger ages showed lower adherence and those living alone had a higher chance of breaking self-isolation. 


\section{Introduction}

As of July 5, 2020, Corona virus disease 2019 (COVID-19) has been confirmed in more than 11 million people worldwide, more than 500000 of whom had died due to complications of the disease (1). An unknown proportion of infected cases remain asymptomatic or undetected; therefore, the true prevalence and case/infection fatality rate remains controversial (2). The novel coronavirus has resulted in an ongoing outbreak of viral pneumonia in Iran since February 19, 2020. By July 5,2020 , the number of laboratory-confirmed cases detected by Iran's surveillance system has reached 240 400 cases with 11571 deaths and over 201210 recovered cases. Soon after the onset of the epidemic, the virus was detected in all provinces of Iran (3-5).

Accumulating evidence suggests that COVID-19 patients' risk increases by age. Studies in Wuhan, China, reported that COVID-19 mortality increases by 3.5 folds in COVID-19 patients of 70-79 years-old rather than younger adults $(5,6)$. This value increases up to 7 folds for patients over 80 years $(1,3,5)$. The same pattern has been reported in other countries as well (7-9). This might (partly) be explained by higher rate of comorbid chronic medical conditions in older adults. Evidence suggests that certain comorbidities increase COVID-19 patients' risk $(2,5,6,10,11)$. A recent meta-analysis on 6 studies (including 1558 COVID-19 patients) revealed an increased risk for COVID-19 patients with hypertension, diabetes, COPD, cardiovascular disease, or cerebrovascular disease (12).

Considering that there is still no vaccine available, self-isolation and physical (social) distancing are proposed as the main control measures, especially in vulnerable populations $(2,9,13)$. While these measures would potentially be efficient, they may have outsized impact on older adults. Restrictions on typical day-today activities, such as limited contact with loved ones and limited social activities, can be an important source of stress, anxiety, and feeling of uncertainty in this population. Under the quarantine situation, older adults would also face difficulty in affording their basic needs, and in receiving their medical and palliative care services. Considering these complications, shielding the elderly would be challenging in practice (14). Depending on the level of stress experienced by older adults, they may relax self-isolation rules. In the worst-case scenario, breaking the isolation may happen leading to the reestablishment of the transmission chain $(15,16)$.

Given the existing challenges for the elderly to meet shielding requirements, it is important to monitor how effective this population has acted in this regard so far. Therefore, this study aims to identify the coverage, efficacy, and continuity of shielding behavior and their predictors in a sample of Iranian older adults. The results would guide policymakers to design tailored interventions.

\section{Methods}

A telephone survey was conducted on 560 Iranian adults aged over 60 years. Participants were selected from a list of older adults who had landline or mobile phone and did not have restrictions for telephone interviews. This information was obtained from the national integrated health portal (ie, SIB portal) in the Ministry of Health and Medical Education of Iran (MoHME). Quota sampling was performed to recruit respondents from 16 cities. The cities were selected with respect to their population size $(\leq 500$ 000 pop $=4$ cities; 500,000 to 1 million pop $=7$ cities; $\geq 1$ million pop $=5$ cities) and geographical location (North $=3$ cities; East $=3$; West $=4$; South $=3$; Central $=3$ cities). In each locality, at least 30 respondents were randomly selected.

Telephone interviews were performed by local trained interviewers using a validated interview form. The interviewer first obtained verbal informed consent. The interview form consisted of 4 parts, including: (a) basic information, eg, age (year), gender (F/M), and living condition (alone, with relatives, other); (b) shielding coverage since the onset of the epidemic in Iran (Feb19) to May 6, 2020 (complete, partial, and no coverage); (c) shielding efficacy in the defined period, which means the percent reduction in the number of contacts $(100 \%, 80 \%-100 \%, 50-80 \%$, and $<50 \%$ ); and (e) shielding continuity in the defined period (yes/no). To develop the interview form, the first draft was developed by the research team based on the study objective and the target population, which were the elderly populations (adults over 60 years). The initial drafts were then checked by 3 experts in the field of geriatric health for its validity and completeness and modifications were made accordingly. The revised form was then initially applied by interviewers and revised based on their feedback. The final version of the interview form was used in this study.

\section{Statistical analysis}

Data were described as mean and standard deviation for quantitative variables and number and percent for categorical variables. Also, the $95 \%$ confidence interval for the proportions was computed using exact score using the Clopper-Pearson method (17). Associations of selfisolation coverage, efficacy, and integrity with age, gender, and living condition were assessed by Chi Square and Fisher's exact tests. Binary logistic regression was used to evaluate the crude and adjusted (pure) effect of age, gender, and living condition (independent variables) on the self-isolation coverage as well as the self-isolation integrity of the elderly (the dependent variables). In the adjusted models, the odds ratios were adjusted for all the abovementioned independent variables (age, gender, and living condition), given that their association with the dependent variable was statistically significant (at 0.2 levels (18)) in the bivariate analysis. Statistical tests were considered as significant at 0.05 levels and as marginally significant at 0.05-0.1 levels. Data were analyzed in SPSS software (version 18).

\section{Ethical statement}

This study was approved by the ethics committee of 
Shahroud University of Medical Sciences (Ethical code: IR.SHMU.REC.1399.049). Participants were informed about study objectives, assured about the confidentiality of their information, and gave their verbal informed consent.

\section{Results}

Data from 558 respondents were finally analyzed in this study (response rate $=99.6 \%$ ). The mean age of the participants was $69.9(\mathrm{SD}=7.4)$ years. Of them, 56.2\% were in the young elderly stage. Also, 54.4\% were female and $85 \%$ were living with at least one family member. Shielding coverage was complete in $61.2 \%$ of the respondents. Also, in $90.1 \%$ of respondents, shielding behavior reduced the number of social contacts by $50 \%$. Continuity of shielding behavior during the defined period (Feb 19 to May 6) was reported by $74 \%$ of the respondents (Table 1 ).

Our results showed a significant association between self-isolation coverage and respondents' gender $(\mathrm{p}<0.0001)$ in a way that females tended to have better self-isolation coverage than males. Females were 2 times more probable to adhere to "complete isolation" than males (OR complete vs. partial: 2.2, 95\% CI: 1.5, 3.1). This association was not changed after adjustment for the confounding effect of age and living conditions in the logistic regression model (Adjusted OR complete vs. partial: 2.3, 95\% CI: $1.5,3.3)$. Chance of partial vs no isolation coverage was not significantly different between males and females

Table 1. Study participants' descriptive characteristics

\begin{tabular}{|c|c|c|c|}
\hline Variables & Number & Frequency & $95 \% \mathrm{CI}$ \\
\hline \multicolumn{4}{|l|}{ Sex } \\
\hline Male & 251 & 45.6 & $39.1,51.8$ \\
\hline Female & 300 & 54.4 & $48.5,60.0$ \\
\hline \multicolumn{4}{|l|}{ Age Group } \\
\hline $60-69$ & 311 & 56.2 & $50.2,61.5$ \\
\hline $70-79$ & 171 & 30.9 & $23.6,37.8$ \\
\hline$\geq 80$ & 71 & 12.8 & $5.9,22.7$ \\
\hline \multicolumn{4}{|l|}{ Living Condition } \\
\hline With Family Members & 465 & 85.0 & $81.3,88.1$ \\
\hline Alone & 72 & 13.2 & $5.8,22.4$ \\
\hline Others & 10 & 1.8 & $0.2,0.5$ \\
\hline \multicolumn{4}{|l|}{ Self-Isolation Coverage ${ }^{1}$} \\
\hline Complete Isolation & 338 & 61.2 & $55.5,66.1$ \\
\hline Partial Isolation & 196 & 35.4 & $28.5,42.3$ \\
\hline No Isolation & 19 & 3.4 & $0.1,26.0$ \\
\hline \multicolumn{4}{|l|}{ Self-Isolation Efficacy ${ }^{2}$} \\
\hline $100 \%$ & 169 & 31.7 & $24.4,38.9$ \\
\hline $80-100 \%$ & 221 & 41.5 & $34.6,47.9$ \\
\hline $50 \%-80 \%$ & 90 & 16.9 & $9.6,25.9$ \\
\hline$\leq 50 \%$ & 57 & 9.9 & $2.9,19.2$ \\
\hline \multicolumn{4}{|l|}{ Self-Isolation Integrity ${ }^{3}$} \\
\hline Yes & 393 & 74.0 & $69.1,78.0$ \\
\hline No & 138 & 26.0 & $18.3,33.4$ \\
\hline
\end{tabular}

tion in the number of contacts due to self-isolation. ${ }^{3}$ Self-isolation integrity is assessed to check if the elderly have broken home isolation during the defined period.

Table 2. Association between the respondents' self-isolation coverage ${ }^{1}$ and their sex, age, and living condition

\begin{tabular}{|c|c|c|c|c|c|c|c|c|}
\hline & \multirow{3}{*}{$\begin{array}{c}\text { Complete } \\
\mathrm{n}(\%)\end{array}$} & \multirow{3}{*}{$\begin{array}{l}\text { Partial } \\
\mathrm{n}(\%)\end{array}$} & \multirow{3}{*}{$\begin{array}{c}\text { No- } \\
\text { Coverage }\end{array}$} & \multirow[b]{3}{*}{$\mathrm{p}$} & \multicolumn{4}{|c|}{ Dependent variable } \\
\hline & & & & & \multicolumn{2}{|c|}{ Complete/Partial Coverage } & \multicolumn{2}{|c|}{ Partial/No-Coverage } \\
\hline $\begin{array}{l}\text { Independent } \\
\text { Variables }\end{array}$ & & & & & $\begin{array}{c}\text { Crude OR }(95 \% \\
\text { CI })\end{array}$ & $\begin{array}{c}\text { Adjusted OR } \\
(95 \% \mathrm{CI})^{4}\end{array}$ & $\begin{array}{c}\text { Crude OR } \\
(95 \% \mathrm{CI})\end{array}$ & $\begin{array}{c}\text { Adjusted } \\
\text { OR }(95 \% \\
\mathrm{CI})^{4} \\
\end{array}$ \\
\hline Sex & & & & & & & & \\
\hline Male & $\begin{array}{c}126 \\
(49.8)\end{array}$ & $\begin{array}{c}113 \\
(44.7)\end{array}$ & $\begin{array}{c}14 \\
(5.5)\end{array}$ & $\begin{array}{c}<0.000 \\
1^{2}\end{array}$ & 1 & 1 & 1 & 1 \\
\hline Female & $\begin{array}{c}212 \\
(69.5)\end{array}$ & $\begin{array}{c}88 \\
(28.9)\end{array}$ & $\begin{array}{c}5 \\
(1.6)\end{array}$ & & $\begin{array}{c}2.2 \\
(1.5,3.1)\end{array}$ & $\begin{array}{c}2.3 \\
(1.5,3.3)\end{array}$ & $\begin{array}{c}2.2 \\
(0.8,6.3)\end{array}$ & $\begin{array}{c}1.8 \\
(0.6,5.3)\end{array}$ \\
\hline $\begin{array}{l}\text { Age Group } \\
60-69\end{array}$ & $\begin{array}{c}182 \\
(57.2)\end{array}$ & $\begin{array}{c}128 \\
(40.3)\end{array}$ & $\begin{array}{c}8 \\
(2.5)\end{array}$ & $0.027^{2}$ & 1 & 1 & 1 & 1 \\
\hline $70-79$ & $\begin{array}{c}108 \\
(63.2)\end{array}$ & $\begin{array}{c}57 \\
(33.3)\end{array}$ & $\begin{array}{c}6 \\
(3.5)\end{array}$ & & $1.3(0.9,2.0)$ & $1.3(0.8,1.9)$ & $\begin{array}{c}0.6 \\
(0.2,2.3)\end{array}$ & $\begin{array}{c}0.6 \\
(0.2,2.0)\end{array}$ \\
\hline$\geq 80$ & $50(70.4)$ & $\begin{array}{c}16 \\
(22.5)\end{array}$ & $\begin{array}{c}5 \\
(7.0)\end{array}$ & & $\begin{array}{c}2.2 \\
(1.2,4.0)\end{array}$ & $2.3(1.2,4.3)$ & $\begin{array}{c}0.2 \\
(0.1,0.9)\end{array}$ & $\begin{array}{c}0.2 \\
(0.1,0.7)\end{array}$ \\
\hline $\begin{array}{c}\text { Living Condition } \\
\text { Alone }\end{array}$ & $52(69.3)$ & $\begin{array}{c}22 \\
(29.3)\end{array}$ & $\begin{array}{c}1 \\
(1.3)\end{array}$ & $0.232^{3}$ & 1 & 1 & 1 & 1 \\
\hline $\begin{array}{l}\text { With family } \\
\text { members }\end{array}$ & $\begin{array}{c}281 \\
(60.0) \\
\end{array}$ & $\begin{array}{r}169 \\
(36.1) \\
\end{array}$ & $\begin{array}{c}18 \\
(3.9) \\
\end{array}$ & & $\begin{array}{c}0.7 \\
(0.4,1.2) \\
\end{array}$ & $\begin{array}{c}1.0 \\
(0.6,1.8) \\
\end{array}$ & $\begin{array}{c}0.4 \\
(0.1,3.3) \\
\end{array}$ & $\begin{array}{c}0.4 \\
(0.1,3.6) \\
\end{array}$ \\
\hline
\end{tabular}


either in the crude logistic model ( $\mathrm{OR}$ partial vs. no-coverage: 2.2 , $95 \%$ CI: $0.8,6.3)$ or after adjustment for the confounding effect of age and living condition (Adjusted OR partial vs. nocoverage: $1.8,95 \% \mathrm{CI}: 0.6,5.3$; Table 2).

We found a positive association between age group and complete vs partial self-isolation in a way that higher age groups showed more probability to completely self-isolate themselves. These associations, however, were only statistically significant for participants older than 80 years when compared to those younger than 70 years (OR complete vs. partial: $2.2,95 \% \mathrm{CI}: 1.2,4.0)$. These associations did not change after adjustment for the effect of sex and living condition (Table 2).

Self-isolation completeness was slightly lower in those who were living with their family members rather than those living alone. However, this association was not statistically significant either in the crude or adjusted models (Table 2).

Percent reduction in the number of contacts (known as "self-isolation efficacy") was slightly higher in females than in males. This association was marginally significant $(\mathrm{p}=0.067)$. In all age groups, most of respondents declared $80 \%-100 \%$ contact reduction, with no significant difference between the 3 age groups in this respect $(p=0.383)$. There was also no significant difference between older adults' living condition and contact reduction rate $(\mathrm{p}=0.314$; Table 3$)$.

The chance of continuing self-isolation was 1.5 folds higher in females than in males (OR: 1.6, 95\% CI: 1.1, 2.4). Adjustment for the effect of age and living condition, slightly increased this chance (OR: 1.8, 95\% CI: 1.2, 2.7;
Table 4).

Participants in older age groups were also more likely to keep the integrity of self-isolation rather than younger age groups. This association, however, was statistically significant, either in crude or adjusted models, for participants older than 80 years when compared to those younger than 70 years (OR crude: 2.6, 95\% CI: 1.9, 3.1; OR adjusted: 2.4, 95\% CI: 1.1, 5.2; Table 4).

Our results showed after adjustment for the effect of age and sex, participants who lived with their family member(s) were 1.2 times more likely to keep the integrity of self-isolation rather than those living alone. This association, however, was not statistically significant ( $\mathrm{OR}$ adjusted: 1.2, 95\% CI: 0.6, 2.1; Table 4).

\section{Discussion}

COVID-19 has shown the ability to overwhelm vulnerable populations, including older adults. The COVID-19 epidemic has also caused rapid changes in health care delivery and restrictions on routine community activities, both of which disproportionately impact the life and wellbeing of older adults. The increase in the COVID-19 CFR with increase in age is well documented in the literature. Empirical data suggest a CFR of $15 \%$ to up to $21.9 \%$ for those aged 80 and older (3). Given the higher risk of COVID-19 complications and mortality in the elderly population, protecting the elderly are among principal preventive efforts that should be started soon and should continue over the course of the epidemic. Thus, monitoring the adherence to self-isolation measures and developing interventions accordingly are of high importance.

Table 3. Association between the respondents' self-isolation efficacy ${ }^{1}$ and their sex, age, and living condition

\begin{tabular}{|c|c|c|c|c|c|}
\hline \multirow[b]{2}{*}{ Variables } & \multicolumn{4}{|c|}{ Self-Isolation Efficacy } & \multirow[b]{2}{*}{$\mathrm{p}^{2}$} \\
\hline & $\begin{array}{l}100 \% \\
\mathrm{n}(\%) \\
\end{array}$ & $\begin{array}{c}80-100 \% \\
\mathrm{n}(\%)\end{array}$ & $\begin{array}{c}50-80 \% \\
\mathrm{n}(\%)\end{array}$ & $\begin{array}{l}<50 \% \\
\mathrm{n}(\%) \\
\end{array}$ & \\
\hline \multicolumn{6}{|l|}{ Sex } \\
\hline Male & $67(28.4)$ & $95(40.3)$ & $51(21.6)$ & $23(9.7)$ & 0.067 \\
\hline Female & $102(34.6)$ & $135(42.4)$ & $39(13.2)$ & $29(9.8)$ & \\
\hline \multicolumn{6}{|l|}{ Age Group } \\
\hline $60-69$ & $98(32.5)$ & $127(42.1)$ & $53(17.5)$ & $24(7.9)$ & 0.383 \\
\hline $70-79$ & $54(32.7)$ & $62(37.6)$ & $26(15.8)$ & $23(13.9)$ & \\
\hline+80 & $17(25.8)$ & $32(48.5)$ & $11(16.7)$ & $6(9.1)$ & \\
\hline \multicolumn{6}{|l|}{ Living condition } \\
\hline With Family Members & $146(32.8)$ & $177(39.8)$ & $78(17.5)$ & $44(9.9)$ & 0.314 \\
\hline Alone & $20(27.4)$ & $37(50.7)$ & $8(11.0)$ & $8(11.0)$ & \\
\hline
\end{tabular}

Table 4. Association between the respondents' self-isolation integrity ${ }^{1}$ and their sex, age, and living condition

\begin{tabular}{|c|c|c|c|c|c|c|c|c|}
\hline \multirow[b]{3}{*}{ Independent Variables } & \multicolumn{5}{|c|}{ Self-Isolation Integrity $^{1}$} & \multirow{2}{*}{\multicolumn{3}{|c|}{ Adjusted Model $^{2}$}} \\
\hline & \multirow{2}{*}{$\begin{array}{c}\text { Yes } \\
\text { n (\%) }\end{array}$} & \multirow{2}{*}{$\begin{array}{c}\text { No } \\
\text { n (\%) }\end{array}$} & \multicolumn{3}{|c|}{ Crude Model } & & & \\
\hline & & & OR & $95 \% \mathrm{CI}$ & $\mathrm{p}$ & \multirow{2}{*}{\multicolumn{2}{|c|}{$95 \% \mathrm{CI}$}} & $\mathrm{p}$ \\
\hline \multicolumn{7}{|l|}{ Sex } & & \\
\hline Male & $161(67.9)$ & $76(32.1)$ & 1 & - & - & 1 & - & - \\
\hline Female & $232(77.6)$ & $67(22.4)$ & 1.6 & $1.1,2.4$ & 0.012 & 1.8 & $1.2,2.7$ & 0.007 \\
\hline \multicolumn{9}{|l|}{ Age Group } \\
\hline 60-69 & $219(71.1)$ & 89 (28.9) & 1 & & & 1 & & \\
\hline $70-79$ & $119(72.5)$ & $45(27.4)$ & 1.1 & $0.7,1.6$ & 0.738 & 0.9 & $0.6,1.4$ & 0.709 \\
\hline+80 & $57(86.4)$ & $9(13.6)$ & 2.6 & $1.9,3.1$ & 0.013 & 2.4 & $1.1,5.2$ & 0.023 \\
\hline \multicolumn{9}{|l|}{ Living condition } \\
\hline Alone & $57(77.0)$ & $17(23.0)$ & 1 & - & - & 1 & - & - \\
\hline With Family Members & $334(74.7)$ & $113(25.3)$ & 0.9 & $0.5,1.6$ & 0.671 & 1.2 & $0.6,2.1$ & 0.643 \\
\hline
\end{tabular}


Our results showed more than half $(61 \%)$ of the respondents fully isolated themselves. Also, most of participants $(72 \%)$ had decreased their social contacts to up to $80 \%$. Also, in the majority of respondents $(74 \%)$, the shielding behavior continued over the defined period.

Elderly with female sex and higher age were more probable to isolate themselves. Being a housekeeper is a typical life style of the majority of elder women in Iran. It has been repeatedly reported that females have better adherence to health-related recommendations, which may partly justify the higher incidence of COVID-19 in men than in women $(19,20)$. Studies also show higher susceptibility of the male gender to COVID-19 infection (21). Therefore, developing gender-specific interventions is highly important to increase cocooning behavior, adherence, and continuity in elder males $(22,23)$.

Percent of the elderly whose contacts reduced up to $100 \%$ decreased in those aged over 80 years. Increase in the cocooning behavior is justifiable as the age increases because older ages are much more associated with comorbidities and general vulnerability to harms and diseases. Comorbidities and disabilities associated with aging can also induce movement restrictions, which fuels cocooning. On the other hand, frail elderlies require more care and support of other people for their basic and health needs, which can justify the lower frequency of contact reduction in the elderly aged over 80 years.

Frequency of $100 \%$ contact reduction in those elderly who live alone was slightly lower than that of those living with their family members. Lonely elders need to get support from other people for their basic needs. They may also be responsible to afford their daily needs themselves, which requires them to go out. Fragile elderlies are unable to access the nutrients they require to survive without relying heavily on support from others. Many elderly patients also do not have the finances to buy enough food to last for a long period of self-isolation. Charities and social campaigns in Iran have acted very well in addressing the needs of vulnerable populations. Charities and volunteers should ensure the elderly do not go hungry as they fear to leave their home and they should also ensure that the elderly can afford their basic needs.

Moreover, the prolonged cocooning in older adults, especially those with comorbidities, may result in healthrelated problems. Older adults are much more likely than other age groups to have inadequate vitamin D status. The role of vitamin D in supporting normal immune function links the importance of adequate vitamin $\mathrm{D}$ status as a protective factor in the Covid-19 pandemic. A nationallyrepresentative population-based study reported that in cold seasons, vitamin D deficiency (25OHD $<30 \mathrm{nmol} / \mathrm{L}$ ) is evident in nearly $50 \%$ of frail elderly and in about $18 \%$ in late middle age. In warmer seasons, vitamin $\mathrm{D}$ deficiency was still common at $31 \%$ in the frail elderly but was lower at about $9 \%$ in late middle age (24-27). Home isolation may aggravate vitamin D status of older adults, which highlights the need for considering vitamin D replacement to supply daily vitamin D requirements. Providing the opportunity for daily exposure to sun light under physical distancing measures would be another alternative, espe- cially for the elderly living in metropolises with mass urbanization.

Mental health issues may also rise as a result of selfisolation. The issue may also be more significant among older adults. Cocooning may intensify the feeling of isolation, which greatly impacts mental health of many elderlies and this could easily lead to depression. Social isolation in itself, both actual and perceived, has been associated with an increased risk of premature death (28). Therefore, it is necessary to develop creative solutions for maintaining effective communications and social ties of the elderly, while keeping them protected against the virus. Contact with family and friends through virtual means have been widely proposed as an available yet inexpensive option $(5,9,14)$. However, the applicability of these services by the elderly is in question, given that many elderlies do not have smart phones or are not familiar with them. Thus, while technology is allowing us to reduce the risk of transmission of COVID-19, it may well be alienating people in our society who arguably require the most help. Systematic and creative plans should be considered to specifically target the elderly in this respect. Also, charities have a good potential to help reduce the increased burden of mental health on the elderly population. To support the population in possible mental health issues during the quarantine, Iran established hotlines that provided mental health services and therapy through phone. Supportive interventions for the elderly during the epidemic may not be similar to those offered for the younger populations, and tailored interventions based on the specific needs and conditions of the elderly may be needed to be put in place. Therefore, online or telephone consulting may not be an efficient method for all elderly subgroups, as many of them do not have or are not able to use these technologies, for whom, tailored interventions should be developed.

\section{Conclusion}

In summary, about two thirds of Iranian elder people adhered to cocooning during the epidemic. Our results can be useful in predicting the epidemic in the future and foreseeing the supply needs. Sample preparation from all parts of Iran and accurate phone questioning are among perceived strengths of this study. However, small sample size and nonrandom sampling in different cities are some of the limitations of this study. It is suggested that a similar study be conducted regionally. The results should foster policy development for epidemic control and maintenance of physical and mental health of the elderly. With the decline of the first wave of epidemics in most countries, protecting the elderly against COVID-19 is still important and necessary (29). With the relaxation of social distancing measures, it is necessary to strengthen the protection of the elderly (30). Public policy goals should prioritize pandemic preparedness in nursing homes, as well as civic and local government-based support programs for community-dwelling older adults to ensure that risk of infection is mitigated while promoting wellness during a period of stress and uncertainty. 


\section{Acknowledgement}

This study is supported by Shahroud University of Medical Sciences in Iran (Code: 9943). The authors would like to thank the interviewers and respondents who participated in this study.

\section{Conflict of Interests}

The authors declare that they have no competing interests.

\section{References}

1.Wu Z, McGoogan J. Characteristics of and important lessons from the coronavirus disease 2019 (COVID-19) outbreak in China: summary of a report of 72314 cases from the Chinese Center for Disease Control and Prevention. JAMA. 2020;323(13):1239-42.

2. Morley JE, Vellas B. COVID-19 and Older Adults. J Nutr Health Aging. 2020;24(4):364-5.

3. Mazumder H, Hossain MM, Das AJJoGSW. Geriatric Care during Public Health Emergencies: Lessons Learned from Novel Corona Virus Disease (COVID-19) Pandemic. J Gerontol Soc Work. 2020:12 .

4. Mounesan L, Eybpoosh S, Haghdoost A, Moradi G, Mostafavi E. Is reporting many cases of COVID-19 in Iran due to strength or weakness of Iran's health system? Iran J Microbiol. 2020;12(2):73.

5. Shahid Z, Kalayanamitra R, McClafferty B, Kepko D, Ramgobin D, Patel R, et al. COVID-19 And Older Adults: What We Know. J Am Geriatr Soc. 2020;68(5):926-9.

6. Jordan RE, Adab P, Cheng K. Covid-19: risk factors for severe disease and death. British Medical Journal Publishing Group; 2020.

7. Remuzzi A, Remuzzi G. COVID-19 and Italy: what next? Lancet. 2020;395:1225-8.

8. COVID C, Team R. Severe outcomes among patients with coronavirus disease 2019 (COVID-19)-United States, February 12-March 16, 2020. Morb Mortal Wkly. 2020;69(12):343-6.

9. Brooke J, Jackson D. Older people and COVID-19: Isolation, risk and ageism. J Clin Nurs. 2020;29:2044-6.

10. Mills JP, Kaye KS, Mody L. COVID-19 in older adults: clinical, psychosocial, and public health considerations. JCI Insight. 2020;5:e139292.

11. Munday D, Leaman J, O’Moore É, Plugge E. The prevalence of noncommunicable disease in older people in prison: a systematic review and meta-analysis. Age Ageing. 2019;48(2):204-12.

12. Wang X, Du Z, Huang G, Pasco R, Fox S, Galvani A, et al. Cocooning is essential to relaxing social distancing. medRxiv. 2020:2020.05.03.20089920.

13. Hellewell J, Abbott S, Gimma A, Bosse NI, Jarvis CI, Russell TW, et al. Feasibility of controlling COVID-19 outbreaks by isolation of cases and contacts. Lancet Glob Health. 2020;8(4):e488-e96.

14. Armitage R, Nellums LB. COVID-19 and the consequences of isolating the elderly. Lancet Public Health. 2020;5(5):e256.

15. Brooks SK, Webster RK, Smith LE, Woodland L, Wessely S, Greenberg N, et al. The psychological impact of quarantine and how to reduce it: rapid review of the evidence. Lancet. 2020

16. Jeong H, Yim HW, Song YJ, Ki M, Min JA, Cho J, et al. Mental health status of people isolated due to Middle East Respiratory Syndrome. Epidemiol Health. 2016;38.

17. Puza B, O'neill T. Generalised Clopper-Pearson confidence intervals for the binomial proportion. J Stat Comput Simul. 2006;76(6):489508.

18. Hosmer Jr DW, Lemeshow S, Sturdivant RX. Applied logistic regression: John Wiley \& Sons; 2013.

19. World Health Organization. Coronavirus disease (COVID-2019) situation reports 171. 2020.

20. Ambrosino I, Barbagelata E, Ortona E, Ruggieri A, Massiah G, Giannico OV, et al. Gender differences in patients with COVID-19: a narrative review. Monaldi Arch Chest Dis. 2020;90(2).

21. Jin JM, Bai P, He W, Wu F, Liu XF, Han DM, et al. Gender differences in patients with COVID-19: Focus on severity and mortality. Front Public Health. 2020;8:152.

22. Gebhard C, Regitz-Zagrosek V, Neuhauser HK, Morgan R, Klein SL. Impact of sex and gender on COVID-19 outcomes in Europe. Biol
Sex Differ. 2020;11(1):1-13.

23. Betron M, Gottert A, Pulerwitz J, Shattuck D, Stevanovic-Fenn N. Men and COVID-19: Adding a gender lens. Glob. Public Health. 2020:1-3.

24. McKenna M, Freaney R, Keating D, Muldowney F. The prevalence and management of vitamin $\mathrm{D}$ deficiency in an acute geriatric unit. Ir Med J. 1981;74(11):336.

25. McKenna MJ, Freaney R, Meade A, Muldowney FP. Prevention of hypovitaminosis D in the elderly. Calcif. Tissue Int. 1985;37(2):112-6.

26. McKenna MJ. Differences in vitamin D status between countries in young adults and the elderly. Am J Med.1992;93(1):69-77.

27. Laird E, O'Halloran AM, Carey D, Healy M, O'Connor D, Moore P, et al. The prevalence of vitamin $\mathrm{D}$ deficiency and the determinants of $25(\mathrm{OH}) \mathrm{D}$ concentration in older Irish adults: Data from The Irish Longitudinal Study on Ageing (TILDA). J Gerontol. 2018;73(4):519 25 .

28. Holt-Lunstad J, Smith TB, Baker M, Harris T, Stephenson D. Loneliness and social isolation as risk factors for mortality: a metaanalytic review. Perspect Psychol Sci. 2015;10(2):227-37.

29. Wang X, Du Z, Huang G, Pasco RF, Fox SJ, Galvani AP, et al Cocooning is essential to relaxing social distancing. medRxiv. 2020.

30. van Bunnik BA, Morgan AL, Bessell P, Calder-Gerver G, Zhang F, Haynes S, et al. Segmentation and shielding of the most vulnerable members of the population as elements of an exit strategy from COVID-19 lockdown. medRxiv. 2020. 